\section{Psicologia Escolar \\ e Educacional}

ARTIGO

DOI: http://dx.doi.org/10.1590/2175-35392021227998

Localizador - e227998

\title{
DIFERENTES PERCEPÇÕES DE MENINOS E MENINAS SOBRE OS ESTILOS DE LIDERANÇA DE PROFESSORAS
}

\author{
Alexia Semzezyn Slobodzian ${ }^{1} \mathbb{D}$; Ana Priscila Batista ${ }^{1} \mathbb{D}$
}

RESUMO

A interação professor(a)-aluno(a) pode repercutir sobre o desenvolvimento infantil, sendo que crenças de professores(as) acerca do comportamento de meninos e meninas podem influenciar suas práticas. $O$ estudo objetivou analisar a percepção de meninos e meninas de 5 ano do Ensino Fundamental sobre os Estilos de Liderança de suas professoras. Participaram 98 crianças de uma escola pública que responderam ao Inventário de Estilos de Liderança de Professores. Os resultados mostraram que meninas perceberam as professoras como mais exigentes $(p<0,05)$ e responsivas $(p=0,06)$ do que meninos. Maior porcentagem de meninos percebeu a utilização de mais alto controle coercitivo por parte das professoras. Quanto aos estilos, houve diferença significativa entre meninas e meninos $(p<$ $0,05)$, destacando-se a porcentagem maior de meninos que percebeu suas professoras como características do estilo negligente. Concluiu-se que houve diferentes percepções entre meninos e meninas sobre professoras, sendo algo importante a ser considerado em estratégias de intervenção no contexto escolar.

Palavras-chave: características do professor; interação professor-aluno; ensino fundamental

\section{Different perceptions by boys and girls of the teachers' leadership styles}

\begin{abstract}
The teacher-student interaction can affect child development, and teachers' beliefs about the boys' and girls' behavior can influence their practices. The study aimed to analyze the boys' and girls' perception in the 5th grade of elementary school about their teachers' Leadership Styles. 98 children from a public school who responded to the Teacher Leadership Styles Inventory participated. The results showed that girls perceived teachers as more demanding $(p<0.05)$ and responsive $(p=0.06)$ than boys. A higher percentage of boys perceived the use of higher coercive control by teachers. As for styles, there was a significant difference between girls and boys $(p<0.05)$, highlighting the higher percentage of boys who perceived their teachers as characteristics of negligent style. It was concluded that there were different perceptions between boys and girls about teachers, which is something important to be considered in intervention strategies in the school context.
\end{abstract}

Keywords: teacher characteristics; teacher student interaction; elementary school

\section{Distintas percepciones de niños y niñas sobre los estilos de liderazgo de profesoras}

\section{RESUMEN}

La interacción profesor(a)-alumno(a) puede repercutir sobre el desarrollo infantil, siendo que creencias de profesores(as) acerca del comportamiento de niños y niñas pueden influenciar sus prácticas. El estudio tuvo por objetivo analizar la percepción de niños y niñas de 5 o curso de la Enseñanza Fundamental sobre los Estilos de Liderazgo de sus profesoras. Participaron 98 niños de una escuela pública que respondieron al Inventario de Estilos de Liderazgo de Profesores. los resultados apuntaron que niñas percibieron las profesoras como más exigentes $(p<0,05)$ y responsivas $(p=0,06)$ de que niños. Mayor porcentaje de niños percibió utilización de más alto control coercitivo por parte de las profesoras. referente a los estilos, hubo diferencia significativa entre niñas y niños $(p<0,05)$, destacándose el porcentaje mayor de niños que percibió sus profesoras como características del estilo negligente. Se concluye que hubo distintas percepciones entre niños y niñas sobre profesoras, siendo algo importante a ser considerado en estrategias de intervención en el contexto escolar.

Palabras clave: características del profesor; interacción profesor-alumno; enseñanza básica

\footnotetext{
${ }^{1}$ Universidade Estadual do Centro-Oeste - Irati - PR - Brasil; alexia.semz@gmail.com; anapriscila@unicentro.br
} 


\section{INTRODUÇÃO}

$\mathrm{Na}$ infância, os contextos em que a criança está inserida são primordiais para o seu desenvolvimento. Seja na família ou na escola, as relações estabelecidas nesses locais podem proporcionar o aprendizado de comportamentos importantes para o desenvolvimento de comportamentos sociais, compreensão de valores e normas que regulam a vida em sociedade, conforme apontam Del Prette e Del Prette (2017).

O ambiente escolar favorece o desenvolvimento das relações interpessoais, pois a criança aprende, nas diversas relações ali constituídas, comportamentos acadêmicos e sociais (Dias, 2016). Além disso, conforme Batista e Weber (2015), as interações no ambiente escolar, principalmente entre professora ${ }^{1}$ e alunos(as), podem propiciar tanto o desenvolvimento cognitivo quanto o desenvolvimento geral da criança. Para Osti e Brenelli (2013) a sala de aula se configura como um espaço rico de troca de conhecimentos e afetos entre professoras e alunos(as).

Alguns dos fatores que influenciam a aprendizagem e a qualidade da relação professora-aluno(a) referem-se ao papel da professora e suas características. Além do conhecimento acadêmico, diversas outras características são destacadas por Martini e Del Prette (2002) como fazendo parte da prática pedagógica, ou seja, as crenças, as expectativas, os sentimentos e as habilidades que professoras e professores possuem.

A prática de um ensino eficaz irá variar dependendo das situações que ocorrem em sala de aula, com base nas interações entre as crianças e a professora (Novak \& Pelaez, 2004). Por conta disso, o modo como a professora percebe seus alunos e alunas pode ser um facilitador ou um impeditivo para o relacionamento e a criação de vínculo, afetando o desempenho das crianças. Segundo Osti e Brenelli (2013):

A representação do professor sobre seu aluno funciona não só como um filtro, direcionando o docente a interpretar o que os estudantes fazem, mas também como um meio de lidar com as aprendizagens e a reagir de forma diferente ante seus progressos e dificuldades (p. 56).

Esses autores afirmam que a criança constrói percepções acerca de si e pode vir a se comportar a partir das expectativas da professora, as quais são construídas por valores e crenças individuais, existindo diversos elementos que podem influenciar esse sistema de expectativas, sendo o gênero da criança uma delas.

A sociedade possui diferenças de raça, classe e

\footnotetext{
1 No presente artigo será utilizado o termo "professora" pelo fato de serem as mulheres a maioria a exercerem essa profissão nos anos iniciais da escolarização. Entretanto, quando citados outros autores, será utilizado o termo empregado por eles.
}

gênero, sendo assim, todos são marcados por essas diferenças que acabam repercutindo na forma como as crianças são avaliadas em seu processo de escolarização. Em relação ao gênero, esse conceito possibilita compreender o significado das complexas interações presentes em nossa sociedade, sendo parte central das relações sociais estruturando a percepção e organização de toda a vida social (Scott, 1995).

A partir desse conceito é possível identificar a naturalização de certos comportamentos, atitudes e vivências baseadas na fisiologia dos corpos e que são impostos pela sociedade e pela cultura. Desde muito cedo, as crianças acabam por desenvolver seus comportamentos a partir daquilo que lhes é esperado. Meninas e meninos são educados de formas diferentes com objetivo de corresponderem a expectativas distintas e que são consideradas mais adequadas para aquele contexto, período histórico e social. Essa diferença ocorre também na educação, onde meninos e meninas são educados de modos diferentes através da forma como familiares, professoras e professores interagem com essas crianças.

Se, por um lado, é possível observar o controle da agressividade na menina, o menino sofre processo semelhante, mas em outra direção: nele são bloqueadas expressões de sentimentos como ternura, sensibilidade e carinho. Os brinquedos oferecidos às crianças também estão carregados de expectativas, simbologias e intenções. As expectativas em relação à diferença de comportamento que se deseja para o menino e para a menina, justificadas pelas diferenças biológicas, acabam proporcionando distintas vivências corporais [...] (Vianna \& Finco, 2009, p. 273).

Essas desigualdades também podem ser percebidas no ambiente escolar; segundo Barbosa, Campos e Valentim (2011) por exemplo, quando professores afirmam possuir uma relação mais amistosa com meninas e mais conflituosa com meninos. Já no estudo de Carvalho (2009) foi possível observar que professores tendem a construir uma visão mais negativa de meninos, principalmente de baixa renda e negros, levando-os a frequentar aulas de reforço mesmo sem problemas de aprendizagem, mas sim pela questão dessas crianças possuírem dificuldades em expressar comportamentos considerados como essenciais no ambiente escolar. Ainda segundo a autora, a questão nesse caso não seria a aprendizagem, mas sim os comportamentos socialmente esperados que estariam em defasagem.

Rodrigues e Mazotti (2013) avaliaram a relação do fracasso escolar e o sexo declarado dos alunos. Em um levantamento com 10.338 crianças foi possível constatar que havia uma associação estatisticamente significativa entre o gênero e o índice de reprovação. 
Ainda os autores ao entrevistarem parte do corpo docente a respeito do que consideravam um bom aluno, obtiveram como resposta diversas características vistas como tipicamente femininas: "[...] a menina é boazinha, calma, não responde à professora, faz todos os deveres, é obediente, e isto já vem de casa...; enquanto o menino é indisciplinado, rebelde, mal educado, agitado, desrespeita a professora" (p. 55).

Em relação ao desempenho escolar, no estudo de Osti e Brenelli (2013) 40 crianças foram indicadas por suas professoras, sendo que 20 apresentavam desempenho acadêmico satisfatório e 20 insatisfatório. Os resultados mostraram que no grupo desempenho acadêmico satisfatório, $65 \%$ dos participantes eram do sexo feminino, já no grupo desempenho acadêmico insatisfatório, os meninos representavam $85 \%$.

Koepke e Harkins (2008) investigaram as diferenças de gênero na relação professor-aluno a partir da perspectiva do professor e da criança através da StudentTeacher Relationship Scale, instrumento desenvolvido por Pianta (2001), sendo aplicado a 35 professoras e professores e 698 crianças. Os resultados apontaram que professoras(es) perceberam suas relações com os meninos como sendo mais distantes e conflituosas, já com as meninas essa relação era percebida como sendo mais próxima e menos conflituosa. Sob o ponto de vista dos alunos, meninos e meninas perceberam seus relacionamentos com seus professores e professoras menos próximos do que era relatado pelos docentes e, além disso, os meninos classificaram sua relação com o(a) professor(a) como sendo mais conflituosa do que as meninas.

Rudasill e Rimm-Kaufman (2009) também apontam a diferença de percepções de professores e professoras em relação aos meninos e meninas. A partir de seus estudos, os autores apontam que meninas estão mais propensas a relações mais próximas e meninos a relações mais conflituosas. Já Mariano e Bolsoni-Silva (2016) constataram em seu estudo que os professores eram menos habilidosos e mais punitivos com meninos e, com isso, também verificaram que as meninas apresentaram maiores médias em habilidades sociais e menos problemas de comportamento. Xavier (2018), ao analisar as percepções dos professores a respeito do desempenho em Matemática de seus alunos, constatou que os professores perceberam diferenças no desempenho de meninos e meninas. A autora relatou que, em um primeiro momento, os docentes diziam não perceber essas diferenças com receio de parecerem preconceituosos com essa afirmação. Entretanto, percebeu-se que a forma de classificação ocorreu por meio do comportamento dos alunos, sendo que o bom comportamento foi associado ao bom desempenho em matemática.

A partir dos estudos acima, observa-se que o gênero é uma variável que pode influenciar o comportamento de professores e professoras. É importante não naturalizar diferenças que são encontradas e sim buscar meios para refletir e analisar mais a fundo essas questões com vistas a compreender como isso pode repercutir nas relações presentes no contexto escolar e no aprendizado do aluno. Entende-se que o papel do/da docente é fundamental e que seu compromisso com a educação está relacionado com a mediação do aprendizado e das relações sociais da criança. Por isso, vale ressaltar que a presença de um clima negativo em sala de aula, com a presença de práticas coercitivas pelas professoras, pode acarretar em prejuízos sobre diversos aspectos do desenvolvimento infantil, conforme aponta Batista (2013).

Diante disso, é importante destacar o modo como professoras e professores mantêm a relação com suas alunas e alunos, pois se a criança percebe que seu/sua professor/a não tem expectativas boas quanto à sua capacidade de desempenho, há grande chance dessa criança entender como algo seu o problema da falta de condições para aprender. Além disso, as relações estabelecidas entre professores/as e alunos/as são importantes para todo o processo escolar e depende da qualidade dessa interação o crescente interesse pela aprendizagem. Como afirmam Osti e Martinelli (2014, p. 10): "as relações com o conhecimento sofrem influências de vivências e experiências com a aprendizagem, as quais podem tanto favorecer quanto inibir o interesse, a criatividade, a motivação, entre outros aspectos necessários ao ato de conhecer".

Para entender mais a respeito da interação professores/as e alunos/as, fez-se uso do modelo teórico dos Estilos de Liderança de Professores, descrito por Batista e Weber (2015, p. 28) como "Conjunto de atitudes direcionadas aos alunos e que, tomadas em conjunto, criam um clima emocional no qual os comportamentos são expressos, moderando a efetividade de uma prática particular e alterando a receptividade da criança à relação de ensino-aprendizagem."

São três construtos que compõem esse modelo teórico: exigência, responsividade e controle coercitivo. A exigência refere-se à capacidade dos(as) professores/as em supervisionar, monitorar e controlar o comportamento dos(as) alunos(as) na tentativa de se fazer cumprir regras e limites dentro da sala de aula e no ambiente escolar. A responsividade diz respeito aos comportamentos do(a) professor(a) em expressar afetividade, demonstrar interesse e preocupação com o bem-estar geral do aluno, ter boa qualidade na comunicação, envolver-se e manter um clima prazeroso e alegre em sala de aula. Por fim, o controle coercitivo refere-se aos comportamentos que o/a professor(a) possui e acabam por impor um clima negativo/aversivo em sala de aula, em que as ameaças e punições inadequadas ao comportamento da criança ocorrem 
independente das regras estabelecidas (Batista \& Weber, 2015; Batista, 2013).

Os comportamentos analisados dentro dos construtos teóricos exigência e responsividade ao serem cruzados identificam quatro estilos de liderança: autoritário, permissivo, negligente e autoritativo, sendo que o controle coercitivo é avaliado à parte. $O$ estilo autoritário pode ser caracterizado como aquele que preza pela ordem e disciplina em sala de aula tendo a maior presença de comportamentos exigentes do que os responsivos. $\mathrm{O}$ estilo permissivo caracteriza-se por mais comportamentos de responsividade do que exigência, muitas vezes propõe as regras, mas acaba por não cumpri-las. $O$ estilo negligente se refere a uma frequência baixa tanto de comportamentos de exigência quanto de responsividade. Por último, o estilo autoritativo apresenta um equilíbrio entre responsividade e exigência, sendo o estilo que apresenta maiores benefícios aos alunos (Batista \& Weber, 2015; Batista, 2013).

Com base no modelo teórico apresentado, foi desenvolvido por Batista (2013) o Inventário de Estilos de Liderança de Professores (IELP) buscando identificar o estilo de liderança de professores e professoras de 40 e 50 anos do Ensino Fundamental. Com a utilização desse instrumento é possível conhecer mais a respeito do estilo de cada docente e assim buscar melhores formas de intervir no contexto da sala de aula e na relação de crianças com seus/suas professores/professoras.

Os estudos acerca dos Estilos de Liderança de Professores e Professoras ainda são relativamente recentes. Ressalta-se a importância de mais estudos que avaliem tais estilos relacionando-os com diferentes variáveis que influenciam a relação professor(a)-aluno(a) e demais situações do contexto acadêmico. Sabe-se que o comportamento em sala de aula do(a) professor(a) pode influenciar o desenvolvimento da criança podendo se apresentar como fator de proteção ou mesmo de risco, dependendo de como se configura (Batista \& Weber, 2015). Diante da importância dessa relação para o funcionamento socioemocional e cognitivo das crianças, faz-se necessário propor investigações que focalizem uma melhor compreensão acerca dos aspectos da interação professor(a)-aluno(a), buscando também compreender as diferenças de gênero que influenciam essa interação. Com isso, a presente pesquisa pretende contribuir com essa literatura e fomentar novas discussões acerca do assunto através de uma análise acerca da percepção de meninos e meninas de 50 ano do Ensino Fundamental sobre os Estilos de Liderança de suas professoras.

\section{MÉTODO}

\section{Participantes}

A pesquisa foi realizada com 98 alunos de quatro turmas de 5o anos do Ensino Fundamental de uma escola pública de um município no interior do Paraná, sendo $44,89 \%$ meninas e $55,1 \%$ meninos. A idade das crianças variou entre 9 e 12 anos sendo sua maioria com 10 anos $(70,4 \%)$.

\section{Instrumento}

O Inventário de Estilos de Liderança de Professores - IELP (Batista, 2013; Batista \& Weber, 2015), versão completa, possui um total de 56 itens que descrevem situações e comportamentos relacionados ao professor, diante dos quais as crianças precisam responder com qual frequência ocorrem apresentando alternativas de resposta do tipo "nunca ou quase nunca", "às vezes" ou "sempre ou quase sempre" caracterizando-o como uma escala Likert de 3 pontos. Dos itens apresentados, 21 são referentes à escala responsividade, a escala de exigência é composta por 16 itens e a escala controle coercitivo é composta por 19 itens. O IELP preenchido por cada participante será corrigido conforme o valor proposto para cada resposta, ou seja, para "Nunca ou quase nunca", será atribuído o valor 1, para "Às vezes", o valor 2 e para "Sempre ou quase sempre", o valor 3. A partir disso, fez-se a soma do valor pertencente às respostas de cada participante aos itens, assim como foram obtidos os escores brutos e o percentil referentes às escalas de responsividade, exigência e controle coercitivo. Para cada escala é verificada na tabela normativa a classificação obtida da frequência com que as práticas educativas das professoras ocorrem, podendo ser classificadas como frequência "baixa"; "tendência a baixa"; "tendência a alta" e "alta". A partir do cruzamento entre as dimensões exigência e responsividade é possível estabelecer os estilos de liderança correspondentes a cada participante como sendo autoritário, permissivo, negligente e autoritativo. Aqui neste artigo apenas serão mencionados os estilos de liderança e não os tipos conforme a frequência de tais práticas. Já o controle coercitivo é analisado à parte e pode ser classificado como "baixo; "tendência a baixo"; "tendência a alto" e "alto", dependendo da frequência dos comportamentos das professoras, sendo classificados a partir da tabela normativa.

\section{Procedimentos}

Após aprovação do Comitê de Ética em Pesquisa (protocolo de aprovação 90738518.7.0000.016), foi realizado o contato com a escola e consultada a disponibilidade em participar do estudo. Após todos os envolvidos estarem cientes da pesquisa, terem se voluntariado para participar, lido e assinado o Termo de Consentimento Livre e Esclarecido (TCLE), no caso de pais e o Termo de Assentimento, no caso dos alunos, deu-se início à coleta de dados. A aplicação do Inventário de Estilos de Liderança de Professores (IELP) aconteceu com quatro turmas do 5o ano do Ensino Fundamental. 
O IELP (Batista, 2013) foi aplicado em cada uma das quatro turmas de forma coletiva em horário de aula no próprio espaço da sala de aula. A aplicação foi conduzida pela pesquisadora e por uma auxiliar de pesquisa, devidamente treinada para isso. Inicialmente foi apresentada a pesquisa, bem como explicado sobre a confidencialidade dos dados e o fato da participação ser voluntária. Os participantes assinaram o Termo de Assentimento e foi solicitado que os participantes não conversassem entre si durante a aplicação do instrumento e que levantassem a mão caso tivessem alguma dúvida. As professoras de cada turma não permaneceram na sala de aula durante a coleta de dados. A forma de preenchimento e resposta aos itens do IELP foram explicadas. A leitura de cada item foi realizada em voz alta pela pesquisadora enquanto as crianças respondiam e tiravam possíveis dúvidas que surgiam ao longo da aplicação. A duração da aplicação foi de 30 minutos em média para cada turma.

\section{Análise de dados}

Para análise dos dados foi realizada a correção do instrumento seguindo manual de Batista e Weber (2015) e utilizou-se o Software Statis. Além da verificação da normalidade dos dados e utilização dos testes $t$ de Student e qui-quadrado. A partir dos dados encontrados, fez-se uma análise do escore médio dos construtos responsividade e exigência, já para o controle coercitivo fez-se uma análise dos quatro tipos.

\section{RESULTADOS}

Inicialmente foi verificada a normalidade da distribuição dos dados da pesquisa, observando: (a) o teste de Kolmogorov-Smirnov, para o qual o valor-p deve ser maior que 0,05 para indicar a distribuição normal dos dados, sendo que o valor obtido nessa pesquisa foi de p>0,05 e (b) a análise do histograma para a observação da distribuição da frequência dos escores obtidos, sendo que o formato de sino indica a distribuição normal, o que aconteceu com os dados da presente pesquisa também. Considerando isso, optou-se por utilizar a análise estatística inferencial paramétrica na comparação entre os grupos, sendo utilizado o teste $t$ de Student. A Figura 1 apresenta os dados referentes à percepção de meninos e meninas quanto às escalas responsividade e exigência.

Na Figura 1, observa-se que o escore na dimensão exigência foi maior para as meninas do que para os meninos, sendo que foi encontrada diferença estatisticamente significativa entre esses grupos ( $t:-2,962$, $p<0,05)$. Para a escala responsividade, observou-se que a média dos escores também foi maior para as meninas do que para os meninos, sendo que foi encontrada uma tendência à diferença estatisticamente significativa entre esses grupos ( $t:-1,857, p=0,06)$.

Na Figura 2 está apresentada a distribuição das respostas entre os tipos de Controle Coercitivo percebido por meninos e meninas.

Na Figura 2 observa-se que um número maior de meninos percebeu o controle coercitivo do tipo 3 (frequência tendência a alta) e do tipo 4 (frequência alta) em comparação a meninas para esses mesmos tipos de controle coercitivo. Já para os tipos 1 (frequência baixa) e 2 (frequência tendência a baixa), mais meninas perceberam o controle coercitivo. Na comparação do escore médio de meninas e meninos nessa escala, não foram encontradas diferenças estatisticamente significativas.

Quanto à percepção dos Estilos de Liderança de Professoras pelas crianças, a Figura 3 apresenta os quatro estilos e a porcentagem de alunos(as) que percebeu cada um deles.

A partir do resultado do teste qui quadrado, observou-se que há relação estatisticamente significativa $\left(x^{2}=9,53, g l=3, p<0,05\right)$ entre os grupos (meninos e meninas) e os Estilos de Liderança adotados pelo pro-

Figura 1. Diferença de Percepção de Meninos e Meninas em Relação às Dimensões Responsividade e Exigência.

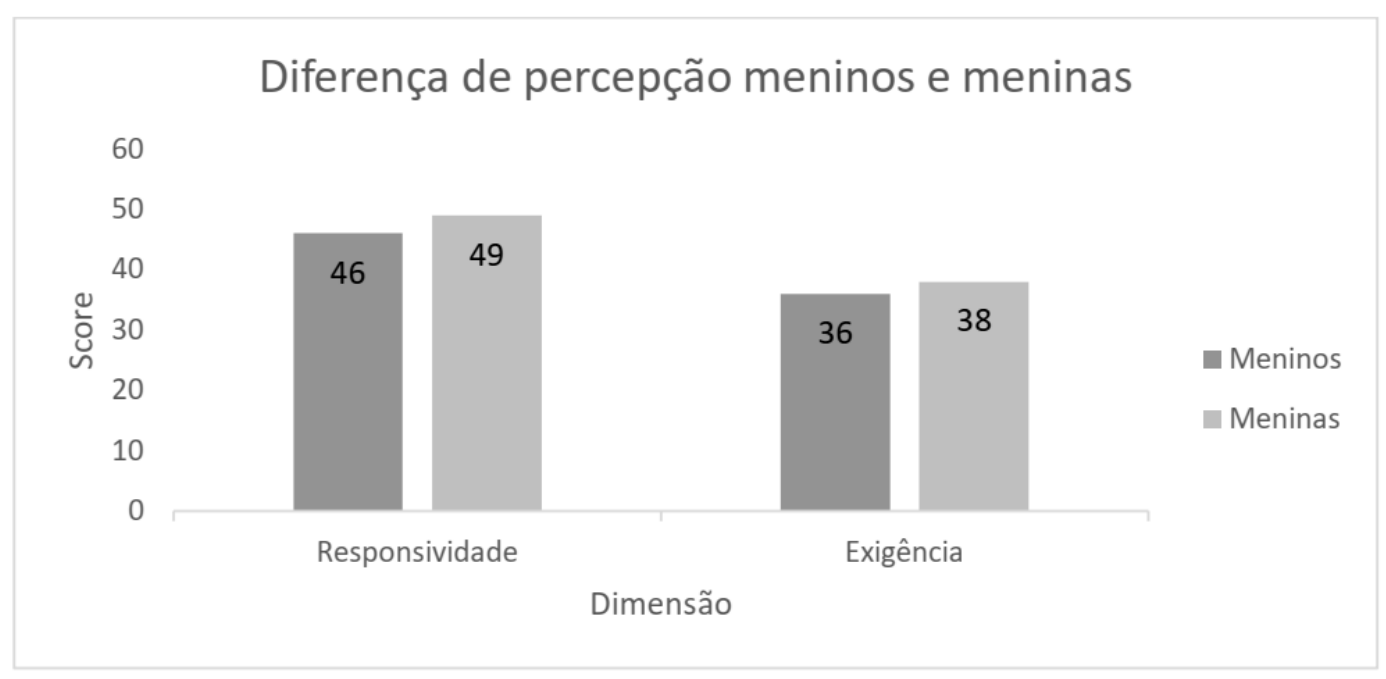


Figura 2. Controle Coercitivo Percebido Por Meninos e Meninas.

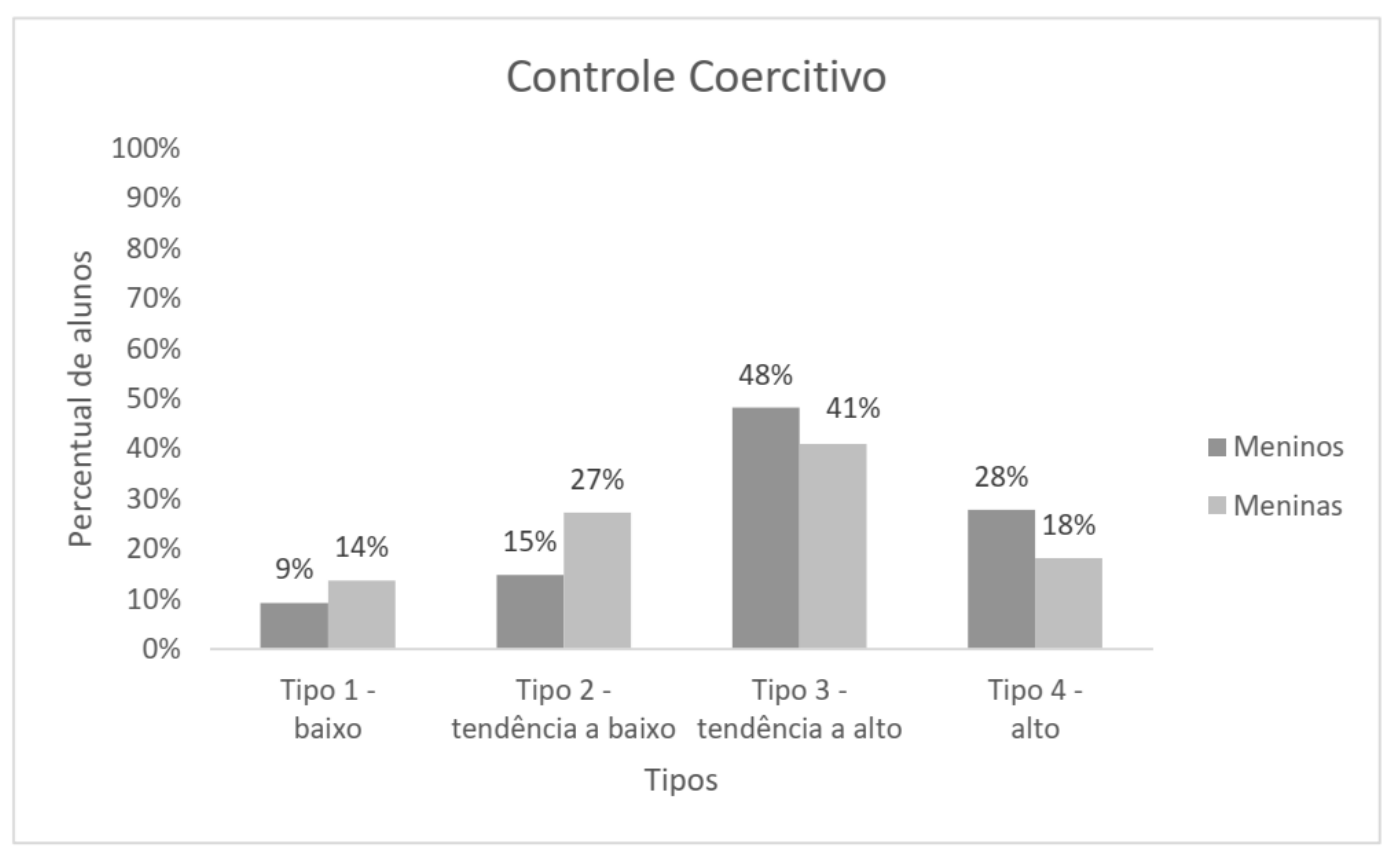

Figura 3. Estilos de Liderança de Professores Percebidos Por Meninos e Meninas.

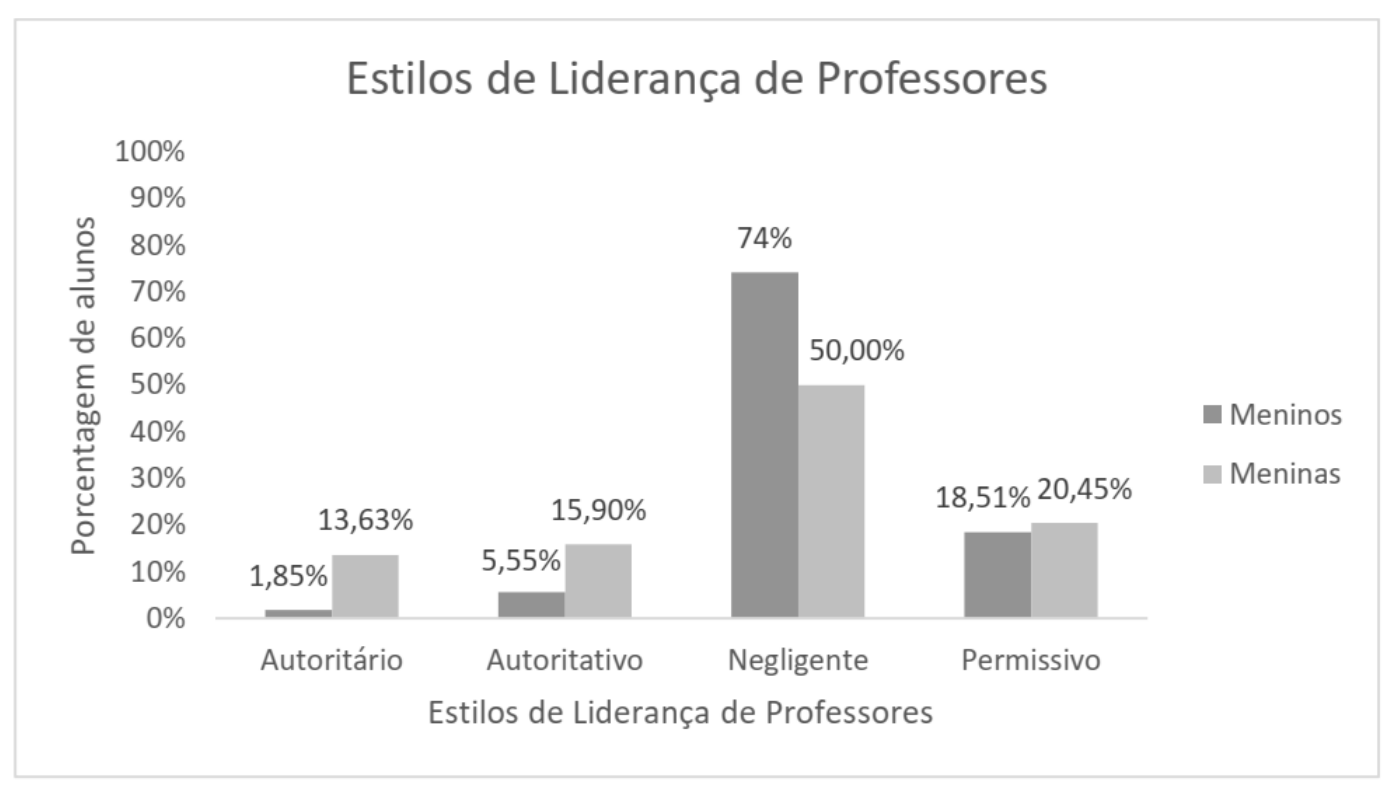

fessor. Foi encontrada maior frequência de meninos que perceberam suas professoras como sendo negligentes. Destaca-se que $74,1 \%$ dos meninos perceberam as professoras como negligentes em comparação a $50 \%$ das meninas. O segundo estilo mais percebido por ambos os grupos foi o permissivo, em que $20,45 \%$ das meninas $(20,45 \%)$ e $18,51 \%$ dos meninos perceberam esse estilo em sua professora. Em relação ao estilo autoritativo e autoritário, as meninas caracterizaram suas professoras com maior frequência de comportamentos referentes a esses dois estilos do que os meninos.

\section{DISCUSSÃO}

De forma geral, os resultados do presente estudo mostram que meninos e meninas percebem de forma diferente as práticas educativas que compõem os estilos de liderança de suas professoras. A partir disso, levanta-se a questão do quanto a percepção da diferença de gênero por parte de professores e professoras pode influenciar nas práticas educativas que utilizam em sala de aula, o que consequentemente repercute sobre a percepção das crianças de tais práticas e estilos de liderança. 
Iniciando pela questão de gênero, conforme Scott (1995), trata-se de um termo que se refere às diferenças entre homens e mulheres a partir de um caráter histórico e cultural, e não puramente biológico. Sendo parte central das relações sociais e da construção das diferenças, "O gênero, então, fornece um meio de decodificar o significado e de compreender as complexas conexões entre várias formas de interação humana" (p. 89).

A escola, por ser um dos principais meios em que a criança está inserida e no qual permanece por um considerável período do seu dia, pode contribuir com este caráter social na formação dos papéis de gênero, sendo que as relações de gênero estão presentes no processo de socialização dos alunos. Segundo Ruis e Perez (2017), dentre as práticas em sala de aula, muitas vezes são reforçados os estereótipos feminino e masculino por meio dos padrões de comportamentos que são esperados e exigidos de cada um, refletindo no modo como as crianças são educadas.

A partir do ponto de vista de que as diferenças de gênero são ensinadas e construídas dentro de um processo, sendo este influenciado também pela interação entre professor(a) e alunos(as), pode-se refletir, sob outro ângulo, a respeito de como isso repercute sobre as percepções que meninos e meninas têm em relação às práticas educativas utilizadas por suas professoras e professores. Osti e Martinelli (2013) apontam que o processo de ensino-aprendizagem é influenciado pelas relações que são estabelecidas no contexto de sala de aula. Isso reflete nas percepções que os alunos terão sobre o seu desempenho e sobre as expectativas que os professores possuem deles, sendo uma relação de influência mútua: a forma como o aluno percebe seu relacionamento com seu professor repercute no seu desempenho e comportamento em sala de aula. Batista (2013) também destaca a relação de influência recíproca entre o comportamento de professores/professoras e alunos(as).

Dessa forma, as características e comportamentos das crianças contribuem também para a percepção que os professores possuem delas e influenciam a forma com que cada professor se comporta diante de cada aluno, repercutindo assim sobre a forma que se dá essa relação.

Um estudo realizado por Bayraktar (2011) buscou analisar as possíveis influências do gênero nas interações entre professor e aluno a partir da observação da relação dos alunos com a professora no momento da correção de textos produzidos por eles. Foram analisados o número e funções das perguntas, frequência de conversas, elogios, fala e interrupções feitas pelo professor. Constatou-se que o professor apresentava diferentes estilos de conferência dependendo do gênero do aluno, sendo que, na relação com as meninas, a conferência teve maior duração, eram mais focadas, tinham mais feedback e as meninas eram mais ativas. Além disso, pode-se constatar, através da Escala de Autoeficácia aplicada e dos textos elaborados, que as meninas eram mais confiantes e competentes do que os meninos em relação às atividades acadêmicas, como a escrita.

Outros autores também estudam essa diferença e apontam que professores afirmam perceberem os meninos como mais indisciplinados, agressivos e desobedientes (Silva, Halpern, \& Silva, 1999; Rudasill, 2011; Maia, Navarro, \& Maia, 2011). No presente estudo, destaca-se a diferença de percepção entre meninos e meninas em relação ao estilo de liderança das professoras, sendo que $74 \%$ da amostra dos meninos perceberam suas professoras como negligentes, ou seja, com baixa responsividade e baixa exigência, enquanto $50 \%$ das meninas tiveram essa percepção. Ao mesmo tempo em que $76 \%$ dos meninos percebeu o controle coercitivo como sendo alto ou tendência a alto, sendo que $59 \%$ das meninas tiveram essa percepção. Esse tipo de relação mais distante e com alto nível de clima aversivo pode acabar gerando uma relação mais conflituosa entre os meninos e suas professoras, produzindo impactos em suas relações futuras. Rudasill (2011) encontrou um resultado semelhante ao examinar, em um estudo longitudinal, as relações do gênero e a qualidade da relação entre o professor e seus alunos no primeiro e terceiro anos, dentre outras variáveis. Nesse estudo, foi constatado que meninos têm uma probabilidade maior de ter conflitos com seus professores no primeiro ano do que as meninas e, da mesma forma, no terceiro ano, professores estavam mais propensos a avaliar a relação com os meninos como sendo mais conflitante do que com as meninas. Para o autor, esses dados sugerem que existem padrões de interação que se perpetuam ao longo dos anos.

Destaca-se a importância de se atentar para a influência do controle coercitivo sobre o desenvolvimento da criança. Sidman (1989/2003) afirma que a presença do controle coercitivo repercute negativamente na relação da criança com a escola, fazendo-a encontrar formas de fugir ou evitar as situações em que será punida, não contribuindo para o ensino de comportamentos mais adequados ao ambiente escolar. Além disso, em muitos casos o aluno sente raiva da escola, sendo comuns casos de vandalismo contra a escola e ataques físicos e/ou verbais aos professores, conforme descritos por Skinner (1968/1972).

Ainda em relação aos resultados encontrados no presente estudo, pode-se constatar que as meninas perceberam suas professoras como sendo mais permissivas, autoritativas, autoritárias e com menor frequência de controle coercitivo do que os meninos. Na dimensão exigência, a média do escore das meninas foi maior do que dos meninos e foram encontrados valores estatis- 
ticamente significativos. Na dimensão responsividade, os valores também foram maiores para o grupo das meninas e tiveram tendência a serem estatisticamente significativos. A partir disso, pode-se dizer que há uma melhor interação das professoras com as meninas do que com os meninos. Maia et al. (2011) apontam, em seu estudo, que as professoras afirmaram que existiam diferenças no manejo do ensino, sendo que as meninas eram favoravelmente vistas como melhores, pois eram "mais responsáveis e dedicadas, o que as tornam mais propensas à aprendizagem" (p. 36). Essa percepção mais favorável por parte das professoras em relação às meninas pode ser uma variável que influencia sobre um clima mais positivo na interação com elas e também pode impactar sobre como as alunas veem essa relação, como no presente estudo em que houve por parte das meninas uma percepção menor do controle coercitivo exercido por suas professoras.

Em consonância, um estudo realizado na Espanha por Menédez (2010) constatou que a maior parte das professoras estava mais interessada nas meninas e as consideravam mais comportadas e obedientes, sendo que os meninos eram vistos como mais agitados, desleixados, com a atenção mais dispersa. A autora afirma que por possuírem comportamentos adequados e bem vistos no ambiente escolar, essas características consideradas como sendo próprias das meninas acabam por facilitar as relações na sala de aula, contribuindo para a criação de um ambiente mais positivo de aprendizagem e influenciando essa percepção mais positiva das alunas em relação a suas professoras.

Gardinal e Marturano (2007), em um estudo realizado na Educação Infantil, também observaram que os professores ao avaliarem o desempenho escolar e os comportamentos de seus alunos, consideraram o comportamento das meninas mais positivamente do que dos meninos. Os professores descreviam os meninos como mais agressivos, desrespeitosos, desobedientes e explosivos enquanto as meninas eram, na visão dos professores, mais respeitosas, tolerantes e controladas.

Em outro estudo (Maia et al., 2011) foi possível verificar que no discurso dos professores, muitos afirmavam que não havia uma diferença entre os sexos em relação aos comportamentos presentes em sala de aula e na relação com a professora. No entanto, os autores constataram que, muitas vezes, o gênero acabava por direcionar as expectativas e as práticas do professor com seus alunos. Assim, salientam a necessidade do aumento das discussões sobre gênero no ambiente escolar e divulgação de produções cientificas da área que visem a elaboração de recursos pedagógicos evitando assim a desigualdade no tratamento de meninas e meninos.

A partir do exposto, observa-se que os dados do presente estudo estão em conformidade com dados da literatura no sentido de que há diferença na interação professor-aluno conforme o gênero. Entretanto, aqui buscou-se analisar a percepção de meninos e meninas sobre essa relação. Já muitos dos estudos apresentados avaliaram a percepção de professores e professoras quanto à diferença nessa interação. De qualquer forma, há uma consonância entre diversos estudos acerca da importância de se considerar o efeito da variável gênero principalmente ao se propor estratégias de intervenção sobre a interação professor-aluno no contexto escolar.

\section{CONSIDERAÇÕES FINAIS}

Com o presente estudo, foi possível constatar as diferenças de percepções que meninos e meninas têm a respeito dos estilos de liderança de suas professoras, sendo que meninos perceberam uma maior frequência de práticas referentes ao estilo negligente, ou seja, perceberam menos práticas relacionadas à exigência e responsividade. Além disso, os meninos também perceberam uma maior frequência de controle coercitivo.

Como limitações à pesquisa aqui relatada, a amostra de alunos que responderam ao inventário foi relativamente pequena, sendo sugerida a aplicação do instrumento a um número maior de alunos para possibilitar uma análise mais ampla. Para futuros estudos, sugere-se que o inventário seja combinado com outros métodos de coleta de dados, como observações em sala de aula, entrevistas com professores e professoras acerca de suas concepções sobre meninos e meninas e entrevistas com as próprias crianças, visando maior abundância de dados e informações para embasar essa discussão. Isso contribuirá para uma análise mais ampla ao considerar também a percepção de professoras sobre a relação com alunos e alunas, bem como para analisar a influência do gênero da/do professor/professora sobre essa relação.

0 presente estudo conclui que existem diferentes percepções de meninos e meninas sobre práticas utilizadas em sala de aula por suas professoras, o que pode repercutir na qualidade das interações estabelecidas e sobre o desenvolvimento infantil.

\section{REFERÊNCIAS}

Barbosa, A. J. G.; Campos, R. A.; Valentim, T. A. (2011) A diversidade em sala de aula e a relação professor-aluno. Estudos de Psicologia, 28(4), 453-461.

Batista, A. P. (2013). Construção e análise de parâmetros psicométricos do inventário de estilos de liderança de professores (Tese de doutorado). Universidade Federal do Paraná, Curitiba, PR.

Batista, A. P.; Weber, L. N. D. (2015). Professores e estilos de liderança: manual para identificá-los e modelo teórico para compreendê-los. Curitiba: Juruá.

Bayraktar, A. (2011). Possible effects of gender on teacherstudent interactions. Procedia Social and Behavioral Sciences, 15, 2545-2548.

Carvalho, M. P. D. (2009). Gênero, raça e avaliação escolar: um 
estudo com alfabetizadoras. Cadernos de Pesquisa, 39(138), 837-866

Del Prette, Z. A. P.; Del Prette, A. (2017). Psicologia das habilidades sociais na infância: teoria e prática (6a ed.). Petrópolis: Vozes.

Dias, M. F. (2016). Estilo de liderança de professores $e$ comportamento acadêmico dos alunos (Dissertação de mestrado). Universidade Federal do Paraná, Curitiba, PR.

Gardinal, C. E.; Marturano, E. (2007). Meninos e meninas na educação infantil: associação entre comportamento e desempenho. Psicologia Em Estudo, 12(3), 541 - 551.

Koepke, M. F.; Harkins, D. A. (2008). Conflict in the Classroom: Gender Differences in the Teacher- Child Relationship. Early Education and Development, 19(6), 843-864.

Maia, A. C.; Navarro, C.; Maia, A. F. (2011). Relações entre gênero e escola no discurso de professoras do ensino fundamental. Psicologia da Educação, 32, 25-46.

Mariano, M.; Bolsoni-Silva, A. T. (2016). Comparações entre práticas educativas de professores, habilidades sociais e problemas de comportamento de alunos. Estudos $e$ Pesquisas em Psicologia, 16(1), 140-160. Recuperado de http://pepsic.bvsalud.org/scielo.php?script=sci_arttext\& pid=S1808-42812016000100009

Martini, M. L.; Del Prette, Z. A. (2002). Atribuição de causalidade para o sucesso e o fracasso escolar dos seus alunos por professoras do ensino fundamental. Interação em Psicologia, 6, 149-156.

Menéndez, M. C. R (2010). La construcción del género en los primeros años de escuela: una mirada desde la perspectiva del profesorado. Revista lberoamericana de educación. Recuperado de https://rieoei.org/historico/ deloslectores/902Rodriguez.pdf

Novak, G.; Peláez, M. (2004). Child and adolescent development: a behavioral systems approach. Califórnia: Sage Publications.

Osti, A.; Brenelli, R. P. (2013). Análise comparativa das relações entre ensino e aprendizagem por professores e alunos. Psicologia Escolar e Educacional, 17(1), 55-63.

Osti, A.; Martinelli, S. C. (2014). Desempenho escolar: análise comparativa em função do sexo e percepção dos estudantes. Educação e Pesquisa, 40(1), 49-59.

Pianta, R. C. (2001). Student-Teacher Relationship Scale: Professional Manual. Odessa, FL: Psychological Assessment Resources, Inc.

Rodrigues, C. A. G.; Mazzotti, T. B. (2013). Representação social de gênero no fracasso escolar de meninos. Revista de Educação Pública, 22(48), 45-59.

Rudasill, K. M. (2011). Child temperament, teacher-child interactions, and teacher-child relationships: A longitudinal investigation from first to third grade. Early Childhood Research Quarterly, 26, 147-156.

Rudasill, K. M.; Rimm-Kaufman, S. E. (2009). Teacher-child relationship quality: The roles of child temperament and teacher-child interactions. Early Childhood Research Quarterly, 24, 107-120.

Ruis, F. F.; Perez, M. C. A. (2017). Ouvindo meninos: relações de gênero na educação infantil. Revista Brasileira de Psicologia e Educação, 19(2), 283 - 294. https://doi.org/10.30715/ rbpe.v19.n2.2017.10922

Scott, J. W. (1995). Gênero: uma categoria útil de análise histórica. Educação e Realidade 20(2), 71-99.

Skinner, B. F. (1972). Tecnologia do ensino (R. Azzi, Trad.). São Paulo: Ed. Herder, Ed. USP. (Trabalho original publicado em 1968).

Sidman, M. (2003). Coerção e suas implicações. Campinas: Editora Livro Pleno. (Trabalho original publicado em 1989).

Silva, C. A. D. da; Halpern, F. B. e S. C; Silva, L. A. D. da. (1999). Meninas bem-comportadas, boas alunas; meninos inteligentes, indisciplinados. Cadernos de Pesquisa, 107, 207-225.

Vianna, C.; Finco, D. (2009). Meninas e meninos na Educação Infantil: uma questão de gênero e poder. Cadernos Pagu, (33), 265-283.

Xavier, F. P. (2018). O menino, com o mínimo de interesse, consegue; a menina tem muito mais afazeres: percepção docente sobre o hiato de gênero no desempenho em Matemática (Dissertação de mestrado). Universidade Federal de Minas Gerais, Belo Horizonte, MG.

Agradecimento à Fundação Araucária pela bolsa concedida para realização desta pesquisa de Iniciação Científica.

Recebido: 29 de agosto de 2019 Aprovado: 26 de fevereiro de 2021 